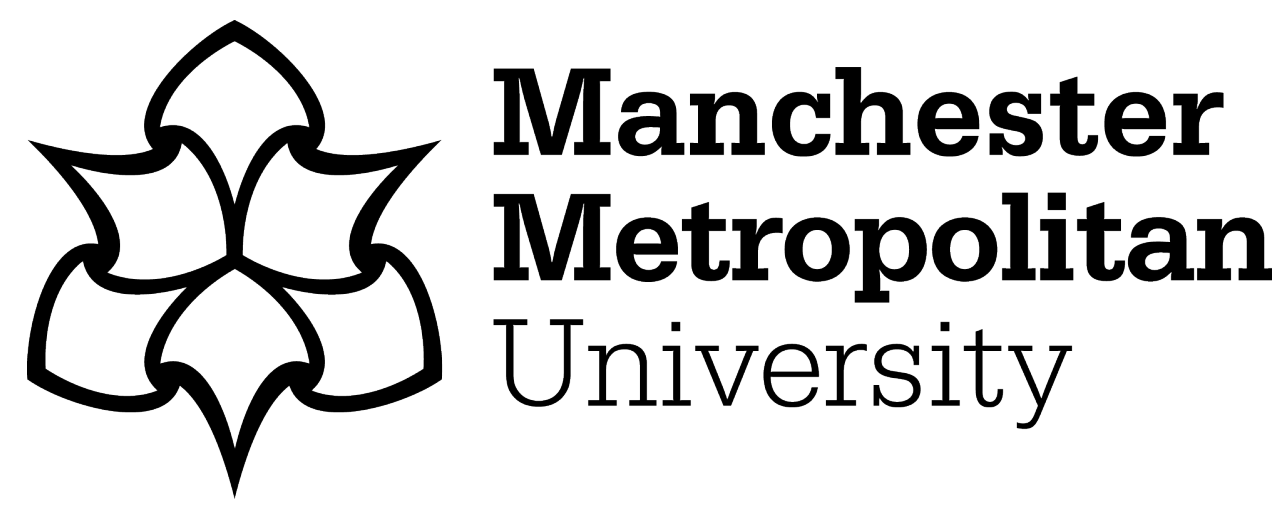

Foley, M and Cummins, I (2015) Reading the death of Mrs A: A serious case review. Journal of Adult Protection, 17 (5). pp. 321-330. ISSN 1466-8203

Downloaded from: https://e-space.mmu.ac.uk/620493/

Publisher: Emerald

DOI: https://doi.org/10.1108/JAP-12-2014-0038

Please cite the published version 


\section{Reading the Death of Mrs A: A Serious Case Review}

\section{Abstract}

Purpose - The purpose is to report the main themes identified into the SCR produced by Surrey Safeguarding Adults Board (SSAB) regarding the suicide of Mrs A in January 2013.

Design -A case study approach is used to examine the SCR. The article links the findings of the SCR with the broader literature, which has examined the experiences of witnesses and complainants in cases of sexual violence.

Findings - The report emphasises that support for witnesses in historic? sexual assault cases has improved but there are still significant gaps in provision. In particular, the systems need to support witnesses for longer after giving evidence. Mental health services need to be more aware of the potential impact of Court cases on victims of sexual violence. The case also highlights the potentially devastating impact of the media reporting of evidence given by victims in rape cases.

Implications - The authors hope that a wider consideration of the circumstances of this case will lead to a greater focus on the needs of victims in cases of historic rape and other sexual assault cases. The SCR highlights that the provision of support for women giving evidence in sexual abuse cases is patchy. Such cases raise very serious ethical issues including the question of how to use the special measures that exist to support vulnerable or intimidated witnesses.

Originality /value - The paper brings together a number of themes in the wider literature and links them to current practice. It also uses a case study approach to exploring the implications for women, in cases of historical sexual abuse, of giving evidence in Court proceedings. 


\section{Introduction}

The publication of the Serious Case Review (SCR) into the suicide of Mrs A (Surrey SSAB2014) revealed once again the stark realities of how difficult it can be for a victim of a sexual offence to stand and testify against an accuser in Court. Keir Starmer, the former Director of Public Prosecutions, has described the system as "barely fit for purpose for victims" (The Guardian 2.4.2014). Mrs A took her own life in January 2013 having given evidence against Michael Brewer. Brewer was a music teacher at Chetham's School of Music in Manchester. He was subsequently found guilty of a series of sexual offences against Mrs A that were committed when she was 14 and 15 . His exwife was also found guilty of indecently assaulting Mrs A when she was 18. Mrs A was a gifted violinist and Brewer a music teacher at the prestigious - but clearly troubled Chetham's. Brewer was able to use his high status, reputation and regular access to oneon-one tuition to isolate and exploit his victims. Mrs A disclosed the abuse to a friend in 2011. The friend contacted the police as she was concerned that Brewer was still working as a music teacher and was in a position to groom other young women. On sentencing, the judge described Brewer as a "predatory sex offender".

The extremely rigorous and detailed SCR (Brown 2014) provides a thorough review of the factors contributing to Mrs A's suicide. This article uses a case study approach to analyse the SCR. Yin (1984:23) describes a case study as "an empirical inquiry that investigates a contemporary phenomenon within its real-life context." This can involve a longitudinal study of a single case but this is not necessarily so. The strength of the case study approach lies in the ability to examine data within the context which it is generated and used. Case studies allow for the examination of the contextual realities of the area being studied. They also allow for the uses of multiple sources of evidence. There is the possibility to explore the gap between what should or is meant to happen and the organisational reality. A case study is not intended as a study of a whole system (Yin 1984). The criticisms of case study approaches echo the wider ones of postpositivism (Bryman 2012). These focus on an alleged lack of rigour and the problem of whether the results are generalizable (Mason, 2002, Neumann, 2013). 
In using a case study approach here, we are seeking to explore the major themes that emerge from the SCR, in particular, the failure of services to recognise the (re) traumatising impact of the court case on Mrs A. This is not to suggest that are not examples where women have been properly supported to give evidence in cases of historic abuse - there are clearly are. By their nature, SCRs are only carried out in incidences where there has been a terrible event such as here. This case highlights that the prosecution of cases of historical sexual abuse pose particular problems. The lack of forensic or other forms of evidence such as eye witness testimony means the trial process, in these cases, focus very much on the behaviour of the complainant. The defence is usually seeking to establish either that the events did not take place or that they were consensual. This is potentially true for all cases of sexual violence but this case indicates that this is particular so when historical cases come to Court. Support for victims giving evidence in cases of historical sexual abuse is vitally important if attempts to prevent re-traumatisation are to be successful.

\section{Introduction to the SCR}

To understand fully the context of the SCR, it is important to provide some background information on the nature of the abuse, to which, Mrs A was subjected. Brewer was a teacher at the world famous Chetham's School of Music in Manchester. Mrs A was a talented violinist and became a pupil at the school at the age of fourteen. She was a boarder at the school. The Brewer case was one of a number of similar cases of teachers sexually exploiting pupils at the school. Our awareness of the nature of sexual abuse, in particular, the grooming process has changed significantly since the late 1970s. However, what the SCR describes as the "catastrophic failure" of the school to ensure that pupils were protected - still shocks. Brewer is not the only member of staff to face charges of sexual abuse. The SCR notes that the specialist nature of Chetham's as a school allowed a culture to develop that was open to exploitation by predators such as Brewer. These features are also apparent in elite sporting and academic institutions where similar incidents of historic abuse have been uncovered (Hadi, 2014). The hot 
house atmosphere combined with individual tutoring means staff have much more individual access to pupils. The nature of that relationship is also different to traditional pupil teacher ones. For example, staff will spend much more time alone with pupils either teaching or taking them to concerts and competitions. The boundaries are very different. In addition, part of the instructor role in developing talent is to encourage the pupils to see themselves as "special". These factors can combine to isolate potential victims from their peers. This isolation has been identified as a key part of the grooming process (Craven et al. 2006, Mcalinden 2006).

Mrs A had been abused by a family member from the age of three until her teens (SSAB 2014:53). She moved to the famous music school at the age of fourteen. There is significant research evidence (Cutajar et al 2011, Lalor and McElvaney, 2010, Najdowski and Ullman 2011) that demonstrates victims of sexual abuse are at risk of revictimisation. Predatory sexual offenders such as Brewer recognise and are able to systematically exploit this vulnerability. Mrs A disclosed the abuse that had taken place at Chetham's, to a family friend in July 2011, when she was living in Surrey with her family. It is important to note that the friend reported this abuse to the police out of concern for other pupils at the school. Greater Manchester Police carried out an investigation. Mrs A agreed to give evidence against her abusers. Brewer and his wife were charged and sent for trial at Manchester Crown Court.

\section{Childhood Sexual Abuse (CSA)}

CSA is identified as a key risk factor in the development of adult mental health problems (Kendall-Tackett et al 1993; Read, 1997). The SCR notes that adult mental health services have significant experience of dealing with women who have been the victims of CSA. Within the research literature, it is apparent that variation in long-term outcomes can be associated with the nature of the sexual violence and relationship with the abuser (Tricke et al, 2001), the child's age and the severity and length of the abuse. These are all factors that can increase the nature of trauma and the potential for adult mental health problems to develop. Finkelhor and Browne (1985:55) outline a model for understanding the traumatic impact of CSA. This model focuses on the dynamics of sexual trauma emphasising that it is sexual abuse 
"An experience that alters a child's cognitive or emotional orientation to the world and cause trauma by distorting the child's self-concept, worldview, or affective capacities".

In this model, there are four dynamics: Traumatic sexualisation, Stigmatisation, Betrayal and Powerlessness. The advantage of this approach is that it offers a nuanced understanding into the potential impacts of CSA. It also focuses on CSA as a process rather than seeing it as an event. This is very relevant in cases such as Mrs A where there are not only a series of offences but also repeated victimisations by different perpetrators.

More recent work has focused on the links between CSA and Post -Traumatic Stress Disorder (PTSD). The PTSD model has been criticised for a narrow focus on some effects, ignoring the context of sexual violence against women and the coping options available to them. Consequently, the model fails to capture the complexities of women's experiences (Kelly, 1988, Wasco, 2003, Campbell and Wasco, 2005). Humphreys and Thiara (2003) argue there are a number of problems with the terminology that is used here - most of which is clearly from a psychological or medical discourse. In their work, Humphreys and Thiara noted that the women that interviewed were more likely to use terms such as "emotional distress". This is a very important issue when exploring the experiences of women giving evidence in Courts. Appearing as a witness carries with it the potential for a direct confrontation with the perpetrator. Stanko and Williams (2009) identified several vulnerabilities, such as age, class and status, which influenced how women reporting rape were responded to within the Criminal Justice System (CJS). These included being young (under eighteen at the time of the offence) and having mental health problems; both factors Mrs A's case.

\section{Prosecuting offences of sexual violence}

Since the 1980s, considerable attempts have been made to improve the quality of recording and investigation practices in rape and sexual abuse cases. This period has also seen the development of specialist provision to meet the needs of victim-survivors. In spite of these efforts practice remains highly variable (Munro and Kelly, 2009). Laville (2009) shows that even the establishment of the specialist Sapphire Unit within the Metropolitan Police did not prevent the cases of serial rapists John Worboys and 
Kirk Reid. In both these cases, there was a repetition of similar failing that have been identified in the past: a failure to act on complaints, a lack of rigorous investigation of assaults and an organisational culture which was, at best, indifferent and at worst hostile to the women who came forward. Despite changes in the law and services to support victim-survivors, rape remains one of the most under-reported crimes (Stern, 2010; Brown et al, 2010). Of those who do report the majority of cases will never get as far as a court hearing (Kelly et al, 2005; Stanko and Willimans, 2009). The attrition rate remains high and cases "fall out" of the CJS at various points. Institutional responses continue to be influenced by stereotypical constructs of rape, rapists and their victims (Estrich, 1986, Munro and Kelly, 2009). These "rape myths" remain extremely powerful both culturally and organisationally. Part of the ordeal that those giving evidence face is having their own behaviour dissected in minute detail through the prism of these myths. Defence lawyers quite properly have to present the best case possible for their clients. It is clear that the defence often feels that these "rape myths" have a potentially powerful influence on the jury.

The investigation process and the court case must be viewed as part of an ongoing ordeal, likely to exacerbate feelings of powerless as their actions are scrutinised and they are forced to recount and relive their ordeal, and the potential for retraumatisation is high. Burman (2009) outlines the impact of hostile questioning aimed at contesting women's credibility, disputing her version and offering alternative explanations. In cross- examination, the character of the victim is often questioned including her mental health status. Horvath et al (2010) highlighted the fact that despite legislation to curtail the questioning of evidence about past sexual history and or the sexual character of the victim-survivor in court, it was still happening. This additional traumatisation has been outlined in first-hand accounts of the investigation and trial in child sexual exploitation cases. When cases do go to court, women will have to recall in public in intimate detail the attack, intensifying negative emotions (Konradi, 2001; 2007). Women had described the experience of giving evidence as a 'second rape' (Stern, 2010). The adversarial legal system combines with the nature of the offence of rape to retraumatise the victim. Obviously, everybody is entitled to defend themselves against any charges they face. However, in sexual offences cases, part of that defence invariably involves a focus on the behaviour of the complainant. For example, the 
defence might argue that sex was consensual or as here that the allegations have been made maliciously. There is a danger that the victims of sexual violence are further victimised and pathologised by agencies that fail to acknowledge adequately the impact of CSA (Hume 2010). The fears and anxieties women have about reporting rape or CSA have to be understood within this context. As do Mrs A's desires to be believed, to obtain justice and her fears that she would not be regarded as a credible witness were acute. Her previous attempts to discuss the abuse in the family were "met with hostility and rejection" (SSAB, 2014:p7) by her adoptive mother and "a disclosure to the housemother" (SSAB, 2014:p8) was not reported or local safeguarding procedures evoked.

Growing awareness of the particular trauma associated with giving evidence in historic rape and sexual abuse cases and the need to provide greater protection to vulnerable victims/witnesses has been recognised in policy and legislation. In an attempt to reduce the stress and anxiety of giving evidence the Youth Justice and Criminal Evidence Act 1999 (YJCEA) introduced a range of special measures available at the court's discretion to enable the victim/witness to provide best evidence. Key measures include the use of screens to shield the woman from the defendant when giving evidence, giving evidence from a separate room via a live video link to the courtroom and giving evidence in private. Under section 16, a vulnerable witness is defined as all child witnesses (under 18); and

Any witness whose quality of evidence is likely to be diminished because they: are suffering from a mental disorder (as defined by the Mental Health Act 1983);

have a significant impairment of intelligence and social functioning; or have a physical disability or are suffering from a physical disorder.

Intimidated witnesses are defined by section 17 YJCEA as those suffering from fear or distress in relation to testifying in the case. Complainants in sexual offences are defined by section 17(4) as automatically falling into this category unless they wish to opt out. (http://www.cps.gov.uk/legal/s_to_u/special_measures/) 
Under these provisions Mrs A was regarded as both a vulnerable and intimidated victim/witness and was interviewed by police officers following the Achieving Best Evidence (ABE) guidelines.

The YJCEA 1999 also has additional provisions to provide protections to vulnerable and intimidated witnesses. These include a prohibition on unrepresented defendants crossexamining complainants in rape and sexual offences. Questions relating to the complainant's sexual behaviour are excluded in rape and other sexual offence cases and the victim/witness has the right to anonymity. The reality is often very different. The anonymity of witnesses is even more difficult to protect in the age of social media. As this SCR noted, upon her death Mrs A's right to anonymity ceased and her identity became public knowledge.

Mrs A's decision not to use the special measures available to her as vulnerable and intimidated witness is discussed within the SCR as a possible indication that at specific points, Mrs A may have lacked capacity. If this were the case, others might have intervened in her best interests and special measures might have been imposed. The imposition of special measures may have protected Mrs A from Brewer's smirking and attempts to intimidate her, but it also had the potential to undermine here. It is important to acknowledge that Mrs A's decision was based on a set of reasonable interlocking fears around credibility and belief. Her fear that she would not be believed was reasonable. On the two previous occasions, she had reported abuse the response from those in positions of trust had been dismissive. Her mother had not believed her when she reported sexual abuse. When she initially spoke to the housemother at Chetham's about Brewer this was not acted upon. Given these circumstances, Mrs A would have benefitted from practical and emotional support to discuss the implications of her choices and to support her fully through the CJS and afterwards.

In our adversarial court system, the role of the defence is clearly to challenge the credibility of the allegation itself. Often they do this by suggesting that the complainant is an unreliable witness. In rape and sexual offences cases, personal difficulties such as the use of alcohol and drugs and/or mental health issues, are often used to undermine 
the credibility of their accounts instead of viewing them as potential indicators that abuse has taken place (Lovett and Horvath, 2009). Despite advice from the DPP that the focus should be on the allegation rather than the complainant, it is the behaviour of women prior, during and after the assault that remain the focus of cross-examinations. This is particularly the case in historical allegations of CSA where there is a limited possibility that there will be any forensic evidence. During the cross examination of Mrs A, she was accused of being a 'liar and fantasist' when she could not exactly recall specific times and dates when she was abused. These issues can take on much greater significance in the Court setting. The defence will seek to use the failure to recall a date or some other detail, for example, what someone was wearing to undermine the overall credibility of the witness and the prosecution case. As noted above, this is potentially an issue in all cases of sexual violence but is increasingly the case in historical cases of CSA. Here, Mrs A was being asked about events that had taken place around thirty years previously. MacMillan and Thomas (2009) note that difficulties of recall and providing a linear account are common experiences amongst adult survivors. This increased in the Court room setting and when dealing with multiple incidences, over a number of years. As the SCR makes clear this difficulty of recall should have been regarded as one of the consequence of coping with multiple incidents of abuse rather than evidence of lies.

In the wider context of the prosecution of sexual abuse cases, it is very easy to understand how Mrs A reached the conclusion that she needed to avoid doing anything that might have the slightest possibility of undermining the case against the Brewers. This included her decision not to accept the special measure offer of giving evidence behind a screen. Mrs A did not want the jury to become aware of her mental health difficulties. She feared it would be interpreted as evidence of her unreliability therefore undermining the veracity of her account. This is an indication of the strength of the hold of "rape myths". It is important to remember here that Mrs A had not made the decision to make a formal complaint against the Brewers but despite this she had agreed to be interviewed and give evidence in court. This was at considerable expense to her wellbeing. The SCR clearly outlines how Mrs A's mental health deteriorated during the investigation, trial and after giving evidence. 
Mrs A's concerns that she might not be believed are likely to have been exacerbated when some of the initial charges against Brewer were dismissed for technical reasons the Court could not be provided with evidence of Mrs A's age at the time of the offences (SCR, p.52). The Daily Mail report of these events was factually accurate. However, the tone of the article was such that it gave the impression that there was no case to answer. This article was open on her Ipad when her body was found (SCR p52). The SCR argues that Mrs A tragically interpreted this article as evidence that she would not be believed. The jury were not informed of her suicide until they had returned their verdict - their decision proved conclusively that they had accepted Mrs A's account. It appears that the full impact of the reporting did not occur until she returned from the court in Manchester to her home in Surrey.

\section{Support Services for women}

Disclosure of abuse can have a positive or negative impact depending on the response given. In Mrs A's case her attempts to tell her mother about the physical and sexual abuse she experienced by a family member was met with anger and blame. The importance of the dynamics of disclosure is vital. A poor response can intensify feelings of self-blame and confusion (McElvaney, 2013). Her experience of telling about the abuse by Brewer was met with apparent official indifference. Neither report resulted in recognition of the harm being done to her or a validation of that these experiences were, indeed, abuse. The experience at Chetham's, - must have added to the already confused nature of her 'relationship' with Brewer. As in similar cases, Brewer was able to exploit this blurring of boundaries. Koss (2006) notes that the initial responses to disclosure have a key role in determining long-term outcomes. Importantly, social support can reduce the severity of the cumulative impacts of multiple victimisations (Brown et al, 2010). Such support was clearly not provided to Mrs A as a child or teenager.

Multiple victimisations made Mrs A more vulnerable, she recognised the impact the investigation and court case on her mental health and sought access to appropriate counselling services. This was not a straightforward process as Mrs A had also formed the impression that she would not be able to access any counselling or therapeutic support as this might compromise or the prosecution case. The SCR clearly states that this was not the case. The Police are clear that Mrs A was never given such a message. 
However, there are limits to the counselling that can take place. Pre-trial therapy is allowed but the focus is on the emotional impact and not on the sexual abuse event. The notes can be disclosed to the defence if they meet the disclosure test. Despite this confusion about whether she could access counselling prior to the trial, the SCR makes it clear that she made several requests for specialist counselling. She also referred herself to Rape And Sexual Abuse Support Centre in Guilford. RSASC could not see her immediately as they had a waiting list. Mrs Aa had requested Psychotherapeutic input but this was declined on the basis that she was not sufficiently emotionally stable enough to benefit from this intervention given the impending trial. No alternative therapeutic interventions were considered or offered to Mrs A. This position was never reassessed.

As the abuse took place in Manchester but as the abuse was disclosed when Mrs A was living in Surrey two police forces - Surrey and GMP - were involved in the case. As the SCR (p11) notes "the division of labour between the two forces created gaps, as well as boundaries, across which information did not pass". Problems in communication and sharing information are frequently identified in Inquiries as a key failing. In Mrs A's case, these difficulties manifested themselves in a number of ways. In preparation for trials in sexual offences case it is common practice for witnesses to be taken on a tour of the Courtroom. This was done in this case but at Guildford rather than Manchester Crown Court where the trial took place. This would have added to Mrs A's distress as viewing the court in which one give's evidence has been identified as a reassuring and important aspect of supporting witnesses.

The role of the police in such cases is a complex and demanding one. The barriers to investigating sexual offences outlined by (Kelly et al., 2005; Stern, 2010; Jordan, 2011) are possibly even greater in cases of historical abuse. The SCR highlights the complexity of the ethical issues that agencies faced here. The police as well as investigating cases also have a much wider remit of protecting vulnerable people. This becomes more complex when that individual is a key witness. As the SCR notes, when Mrs A came forward to give her statement she had every right to keep her privacy in other areas of her life, including her history of mental health problems. These issues were complicated 
by the role confusion that developed. The Witness Care Unit was based in Surrey but Victim Support services for the trial were provided in Manchester. Mrs A was not regarded as a vulnerable adult, at least initially, so no referral was made by either police force under Safeguard Vulnerable Adults protocols. This is a result of a misunderstanding of the pressures that complainants in rape and sexual assault cases face. The nature of the impact of the abuse on Mrs A meant that she was vulnerable and increased in the build-up to the trial.

\section{Mrs A and Mental Health Services}

The possible impacts of CSA on the mental health of adult survivors are well documented (Dinwiddie et al 2000, Horwitz, et al 2001, Kendler et al 2000). Significant numbers of women particularly, but also men who use mental health services are coping with the long-term effects of sexual violence (Cutajar et al 2011). It is, therefore, surprising that mental health services involved with Mrs A do not appear to have fully acknowledged this. As the SCR argues the nature of previous abuse by a family member, the high profile Brewer trial and the ordeal of giving evidence should have alerted staff involved in her care to the increased pressure she faced. Mrs A was unclear about what information about the nature of the abuse she could share with those involved in her care. She was clearly concerned that she might prejudice the trial in some way.

One of the strongest findings of the SCR was that professionals involved in her care should have been more pro-active. In early 2012, Mrs A. approached the (RASASC) in Guildford for support but was informed that there was a five-month waiting list. From April 2012 onwards, a pattern of Mrs A overdosing on prescribed medication developed. The SCR records ten such overdoses before her death in January 2013. Despite the frequency and increasingly serious nature of the attempts, Mrs A was consistently as assessed as being low risk. It is surprising that this pattern did not lead to some consideration of an inpatient admission. For example, it appears she was never assessed with a view to admission under the Mental Health Act. The MHA Code of Practice is clear that the least restrictive alternative should be used and compulsory admissions are to be avoided. However, there is a concern that these attempts to 
manage Mrs A's mental health crises without the use of compulsory powers added to rather than reduced the risks. The SCR (p32) highlights the structural pressures on services - for example high sickness rates and the lack of clinical psychology input - that provide the context, in which; professionals make individual decisions regarding risk. Even allowing for the service context, the SCR is unusually forthright in its comments about the management of Mrs A's mental health. One would expect that mental health professionals would be particularly attuned to the potential impact of CSA and the pressures of giving evidence.

\section{Discussion}

It is important to acknowledge that the death of Mrs A is a tragedy for her family and friends. In examining the SCR for lessons for professionals and organisations, it is vital that we do not lose sight of the pain and distress that she and her family have endured. We have used this SCR as a case study - a means of examining the broader concerns about the treatment of victims of sexual violence throughout the prosecution process. This is not to say that all cases can be compared to Mrs A's. However, the main themes from the report provide insights into the failings of the systems designed to support victims of sexual violence. This case also shows the complex nature of support that needs to be provided to address the long-term impact of CSA. The Court setting is one that requires particular attention because of the pressures it places on women giving evidence. The support for complainants in rape and sexual assault cases has improved, but it would be foolish to assume that there is not scope for more work in this area. The media reporting of this case and others demonstrates how deeply engrained rape myths are within the wider culture. Mrs A's clash with the defence counsel shows that she was acutely aware of this herself. These myths can only be countered by continued campaigns and education.

One clear message from the SCR is that we need to re-examine the support that is provided for complainants in these sorts of cases. Special measures alone are not able to deal with the emotional impact that confronting an abuser creates. They can assist the person to give evidence but they do not deal with the aftermath. As the SCR suggests, expert evidence on the impact of sexual violence would put the use of such measures in 
a context for the jury. The authors would argue that the SCR identifies a need for much greater investment in specialist services both in the public and voluntary sectors to support victims through the legal process. As the SCR illustrates confusion arose between agencies over what information, if any, they could share and other issues. There is a clear potential conflict between the evidence-gathering role of the Police, prosecutorial role of the CPS and the wider duty to support witnesses and victims in such cases. The evidential and procedural needs can conflict with the emotional and wider support that complainants require.

In this case, the strain of the disclosure and evidence process clearly put Mrs A's mental health at risk. Her repeated requests for additional support were not met and it is vital that mental health services recognise and respond appropriately to the stress involved in women giving evidence in court and in the aftermath of the court hearing. The system needs to balance the needs of the legal system with the needs of women reporting these crimes. One of the possible effects of the cross-examination is to echo the marginalising the testimony of the victim that is part of the process of abuse. In this case, the judge intervened to suggest that a screen should be placed between Brewer and Mrs A. Part of her reasoning for rejecting this support was that if her belief that if did not confront him in open Court then the jury would be less inclined to believe her testimony.

There is some evidence to suggest that technology such as video recordings aimed at helping vulnerable victims can diminish the impact of their testimony (MacMillan and Thomas, 2009). As noted above, this is a belief that is rooted in the research into lived experience of women who have given evidence in similar circumstances. Ellison and Munro (2010) concluded that the mode of the delivery - i.e with or without special measures- did not have a significant impact on the jurors' perceptions of credulity. Credibility was linked to the jurors' beliefs about injury and resistance. Smith and Skinner (2012) argue that the evidence regarding the effectiveness of special measures is, at best, mixed. It may reduce some women's anxieties but the combative adversarial system makes this difficult. Such a system is based on a rational, technocratic approach. It judges people's behaviour within this framework even though people may behave in irrational ways. For example, rational ideas of reporting may be used to suggest that a delay in reporting means that the allegation is suspicious. In addition, "beyond 
reasonable doubt" means that any doubt should lead to acquittal. It is possible that introducing victims' lawyers may address some of these issues.

In the absence of forensic evidence, the jury is thus called upon to assess the competing accounts. The SCR (p53) suggests that one possible solution would be for the judge to be able to decide that special measures must be used. The SCR argues that this would mean that it would be impossible for the jury to make any inference about the credibility of the witness. This raises a very important point - would it be ethical or practical to impose the use of special measures in the case of adult witnesses who decline it. Whilst one might strongly advise such witnesses to take advantage of the protections that special measures might offer, the authors would not agree with the overriding of an expressed wish not to do so. The main argument would be that to ignore the wishes of the complainant would be another example of their voice not being properly heard. On a practical level, it is difficult to see how a witness could be forced to give evidence from behind a screen. Screens are an important in the support and protection of vulnerable witnesses but they are unlikely to diminish the emotional impact of giving evidence and being cross-examined and called a 'liar' or 'fantasist'. Mrs A recognised she needed additional support during the investigation and court case and critically after giving evidence but this was not forthcoming. It seems impossible to come up with blanket guidance in such cases. Some fundamental principles should form the basis for the way forward. The most important of these is that the complainant should be involved in every stage of the decision making process.

Mrs A's suicide has echoes of two other high profile cases. Earlier in 2014/ 15 Tracy Shelvey gave evidence in two trials in Manchester; she stepped off the roof of a shopping centre three days after a man was found not guilty of raping her. Corporal Anne-Marie Ellement, a military policewoman, committed suicide in 2011 following a decision by the authorities not to prosecute two soldiers who she had reported raped her. The coroner concluded that bullying and the "lingering" effect of the alleged rape both played a role in her death and called for the Ministry of Defence to review its care for vulnerable soldiers. These cases emphasise that the system is failing to support individuals when they approach authorities with allegations of sexual abuse. As the SCR concludes 
"Mrs A had reasons to live and she continued to ask for help throughout this period ... When historic cases of sexual abuse come to court, we ask former victims to stand up and lay bare details about their lives that are painful and intimate. Criminal justice and mental health services should be able to provide a comprehensive and seamless support service to them throughout this process because, as this case demonstrates, historic abuse is always a present source of difficulty and distress to those who have been victimised."

This is a message that all those working in the CJS, mental health services and any agency working with the impact of sexual violence needs to heed if similar failings are not to be repeated. It is also one that needs to be taken further afield so that the deeprooted cultural ideas that minimize the impact of sexual violence or seek to place the responsibility for such acts on victims are challenged on a consistent basis.

\section{References}

Brown, H The Death of Mrs A: A Serious Case Review

http://www.surreycc.gov.uk/ data/assets/pdf file/0011/815384/FINAL-Mrs-A-fullreport-26.03.14.pdf

Brown , J., Hovarth, M., Kelly, L., and Westmorland, N (2010) Connections and Disconnections: assessing evidence, knowledge and practice in response to rape. Project Report. Government Equalities Office, London.

Bryman, A (2012) Social Research Methods Oxford OUP Campbell, R and Wasco, SM (2005) Understanding Rape and Sexual Assault 20 Years of Progress and Future Directions Journal of Interpersonal Violence vol. 20 no. 1 127-131 Craven, S., Brown, S., \& Gilchrist, E. (2006) Sexual grooming of children: review of literature and theoretical considerations. Journal of Sexual Aggression, 12, 287-299. 
Cutajar, M Ogloff, J and Mullen, P (2011) Child Sexual Abuse and Subsequent Offending and Victimisation: A 45-year Follow-up Study Report to the Criminology Research Council http://crg.aic.gov.au

Dinwiddie, S., Heath, A. C., Dunne, M. P., et al (2000) Early sexual abuse and lifetime psychopathology: a co-twin control study. a co-twin control study. Psychological Medicine Ps 30, 41-52. ,

Ellison, L and Munro, V (2010) A Stranger in the Bushes, or an Elephant in the Room? Critical Reflections Upon Received Rape Myth Wisdom in the Context of a Mock Jury Study New Criminal Law Review: An International and Interdisciplinary Journal Vol. 13, No. 4 , pp. 781-801

Estrich, S (1986) Rape The Yale Law Journal 95 (6) 1087-1184

Finkelhor, D and Browne, A (1985) The traumatic impact of child sexual abuse: A conceptualization. American Journal of Orthopsychiatry, Vol 55(4), 530-541.

Hadi, J (2014) We don't listen to children when it comes to abuse in sport https://theconversation.com/

Hewson, B (2013) Yew tree is destroying the rule of law http://www.spikedonline.com

Horwitz, A.V., Spatz Widom, C., McLaughlin, J., Horwitz, A.V., Spatz Widom, C., McLaughlin, J., et al (2001) The impact of childhood abuse and neglect on The impact of childhood abuse and neglect on adult mental health: a prospective study. Journal of Health and Social Behavior, 42, 184- 201.

Hume, T. (2010) Conflicting interests? Sunday Star Times, 29 August 2010, p. 1 Humphreys, C. and Thiara, R. K. (2003) Domestic violence and mental health: 'I call it symptoms of abuse" British Journal of Social Work 33: 209-26

Jordan, J. (2004). Beyond belief? Police, rape and women's credibility. Criminal Justice, $4,25-59$. 
Jordan, J (2011) Here we go round the review-go-round: Rape investigation and prosecution-are things getting worse not better? Journal of Sexual Aggression: An international, interdisciplinary forum for research, theory and practice, 17:3, 234-249

Kelly, L (1988) How women define their experiences of violence Feminist perspectives on wife abuse, edited by Kersti Yllo and Michele Bograd. Newbury Park, California, Sage Publications

Kendall-Tackett, K Williams, L; Finkelhor, D (1993) Impact of sexual abuse on children: A review and synthesis of recent empirical studies. Psychological Bulletin, Vol 113(1)

Kendler, K. S., Bulik, C. M., Silberg, J.,et al (2000) Childhood sexual abuse and adult psychiatric and substance use disorders in women: an epidemiological substance use disorders in women: an epidemiological and cotwin control analysis. Archives of General Psychiatry57 953- 959

Lalor, K. and McElvaney, R. (2010).Child sexual abuse, links to later sexual exploitation/high-risk sexual behavior, and prevention/treatment programs. Trauma, Violence, \&Abuse, 11,159-177

Laville, S. (2009) Rape investigations unit launched as Met aims to target serial attackers. Scotland Yard sets up $11.4 \mathrm{~m}$ intelligence team in response to failures in Worboys and Reid cases. The Guardian, 2 December 2009, p. 7.

Lea, S, Lanvers, U and Shaw, S (2003) Attrition in Rape Cases Developing a profile and identifying relevant factors. British Journal of Criminology 43 583-599

Lovett J and Horvath M (2009) Alcohol and drugs in rape and sexual assault. In: Horvath and Brown J (Eds) Rape: Challenging Contemporary Thinking. Portland, Oregon: Willan Publishing, pp. 125-160.

Mason, J (2002) Qualitative Researching London Sage

McAlinden, A.M. (2006) Managing risk: From regulation to the reintegration of sexual offenders. Criminology and Criminal Justice, 6, 197-218 
McElvaney, R. (2013), Disclosure of Child Sexual Abuse: Delays, Non-disclosure and Partial Disclosure. What the Research Tells Us and Implications for Practice. Child Abuse Review

McMillan, L., \& Thomas, M. (2009) Police interviews of rape victims; tensions and contradictions. In M. A. Horvath \& J. Brown (Eds.), Rape: Challenging contemporary thinking (pp. 255 280). Cullompton: Willan.

Mossman, E., MacGibbon, L., Kingi, V., \& Jordan, J. (2009). Responding to sexual violence: Environmental scan of New Zealand agencies. Wellington: Ministry of Women's Affairs.

Najdowski, C and Ullman, S (2011) The effects of revictimization on coping and depression in female sexual assault victims Journal of Traumatic Stress Volume 24, Issue 2, pages 218-221

Neuman, W. (2013) Social Research Methods: Qualitative and Quantitative Approaches Harlow Pearson

Read J. (1997) Child abuse and psychosis: a literature review and implications for professional practice. Prof Psychol Res 28:448-456

Smith, $O$ and Skinner, T (2012) Observing Court Responses to Victims of Rape and Sexual Assault Feminist Criminology vol. 7 no. 4 298-326

Stanko, B., \& Williams, E. (2009) Reviewing rape and rape allegations in London: What are the vulnerabilities of the victims who report to the police? In M. A. H. Horvath \& J. Brown (Eds.), Rape: Challenging contemporary thinking (pp. 207-227). Cullompton, Devon: Willan Publishing.

Stern, Baroness V. (2010) Stern review of rape reporting in England and Wales. London: Home Office

Trickett PK, Noll JG, Reiffman A, and Putnam F (2001). Variants of interfamilial sexual abuse experience: Implications for long-term development. Journal of Development and Psychopathology. 13:1001-1019.

Wasco, SM (2003) Conceptualizing the Harm done by Rape Applications of Trauma Theory to Experiences of Sexual Assault Trauma Violence Abuse vol. 4 no. 4 309-322 
Yin, R.K., (1984). Case Study Research: Design and Methods. Beverly Hills, Calif: Sage Publications. 